\title{
A Clinico-Pathological Study of Cervical Lymph Nodes
}

\author{
Gaurav Batni $^{1,2} \cdot$ Sushil Gaur $^{1} \cdot$ O. N. Sinha ${ }^{1} \cdot$ Siddhant Priya Agrawal $^{1} \cdot$ \\ Abhinav Srivasatva ${ }^{1}$
}

Received: 4 July 2016/Accepted: 2 August 2016/Published online: 5 August 2016

(C) Association of Otolaryngologists of India 2016

\begin{abstract}
Cervical lymphadenopathy is one of the commonest presenting complaint of patient in ENT OPD Fine Needle Aspiration Cytology (FNAC) is one of the most reliable, less expensive, and basic diagnostic procedure for the definitive and conclusive diagnosis for the immune system which reciprocates in the form of enlarged lymph nodes. A study was conducted in ENT Department of Santosh Medical College, Ghazibad from August 2015 to May 2016 on 64 patients with enlarged cervical lymph nodes. FNAC was done to make the diagnosis. Out of 64 patients $(51.5 \%)$ was reactive non-specific, $28 \%$ tubercular, $3.1 \%$ lymphoma and $17 \%$ were malignant. FNAC is one of the most dependable diagnostic tools in case of cervical lymphadenopathy for early diagnosis and detection for the better management.
\end{abstract}

Keywords Fine needle aspiration cytology ·

Cervical lymph nodes $\cdot$ FNAC $\cdot$ Cytology

\section{Introduction}

The neck consists of nearly $2 / 3$ rd of the total lymph nodes of the body. The enlargement of these lymph nodes is quite significant in that there are so many etiological agents and is an index spread of infections and malignancy [1].

Gaurav Batni

gaurav_batni@yahoo.com

Santosh Medical College and Hospital, Ghaziabad, India

246 Ansal Pradhan Enclave, E-8 Extension Arera Colony, Bhopal, Madhya Pradesh, India
Acute infective lymphadenopathy is usually self-limiting and settles with antibiotic therapy but abscess formation may occur which may require aspiration or Incision and Drainage [2].

Tuberculosis has evolved into a number of widely distributed and genetically diverse and sub-linages exhibiting variable disease phenotypic characteristics demonstrated in epidemiological studies and animal models. This together with diversity of the host immunological response may explain the wide clinical immune-pathological spectrum of the disease in those patients who cannot control the infections [3-5].

Sensitivity and specificity of Fine Needle Aspiration Cytology (FNAC) have been documented in several studies $[6,7]$.

One of the commonest presenting complaints of patient in ENT OPD is Cervical Lymphadenopathy. Etiology may vary from simple inflammation to malignancies and tuberculosis, sometimes it may be non-specific.

Tubercular lymphadenitis is one of the most common causes of enlarged cervical lymph nodes in India. It is differentiated by Fine Needle Aspiration Cytology (FNAC) which is one of the most reliable, less expensive and basic diagnostic procedure [8] for the definitive and conclusive diagnosis immune system reciprocates in the form of enlarged lymph nodes depending on their drainage [9]. Neck masses are a common concern in infants, children as well as in adults [10].

\section{Materials and Methods}

This study was conducted on 64 patients who attended the ENT OPD of Santosh Hospital, Ghaziabad (U.P.) with enlarged cervical lymph nodes; from August 2015 to May 
2016. FNAC was done for all Cervical Lymph Nodes and were included in the study. Cases were reviewed for age/sex/diagnosis.

Cytologically epithelioid and Langerhan's giant cells were reported as tuberculosis lymphadenitis with lymphoid cells and metastatic malignancy was classified.

\section{Results}

Total number of patients was 64, who underwent FNAC for enlarged cervical lymph nodes. Demographic profile is shown in Table 1.

Profile shows male preponderance with mean age in the mid of third decade.

The pattern of cervical lymphadenopathy is shown in Table 2.

Almost half of the lymph nodes $(51.56 \%)$ were reactive without a known cause which was followed by tubercular $(28.12 \%)$ (Fig. 1); malignancy (17.18\%) (Fig. 2) and lymphoma (3.1\%) cases were accounted. Higher incidence of malignancy was seen in (51-60) and (more than 60) age group. Tubercular lymphadenitis was common in (21-30) age group.

Table 1 Demographic profile

\begin{tabular}{lll}
\hline Particulars & Numbers & Percentage (\%) \\
\hline Male & 34 & 53.1 \\
Female & 30 & 46.9 \\
\hline Age range 2-80 years & \\
\hline Age group (in years) & Numbers \\
\hline $2-10$ & 07 \\
$11-20$ & 10 \\
$21-30$ & 18 \\
$31-40$ & 13 \\
$41-50$ & 06 \\
$51-60$ & 05 \\
More than 60 & 11 \\
\hline
\end{tabular}

Table 2 Pattern of cervical lymphadenopathy

\begin{tabular}{llc}
\hline Cytological diagnosis & Number & Percentage $(\%)$ \\
\hline Reactive non-specific & 33 & 51.56 \\
Tubercular & 18 & 28.12 \\
Lymphoma & 02 & 3.1 \\
Metastatic carcinoma & 11 & 17.18
\end{tabular}

Total number of patients-64

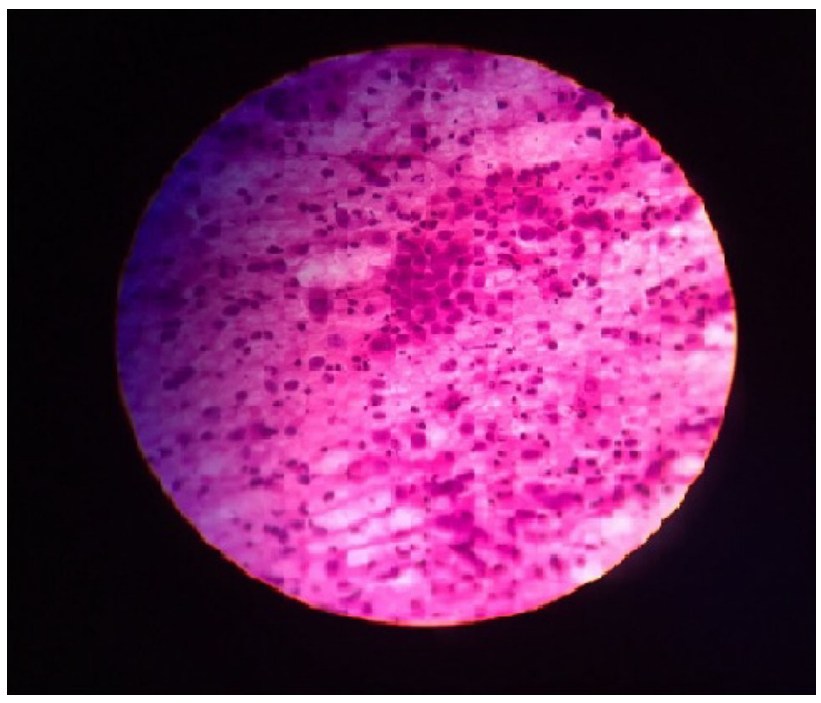

Fig. 1 Histopathological slide showing tuberculosis

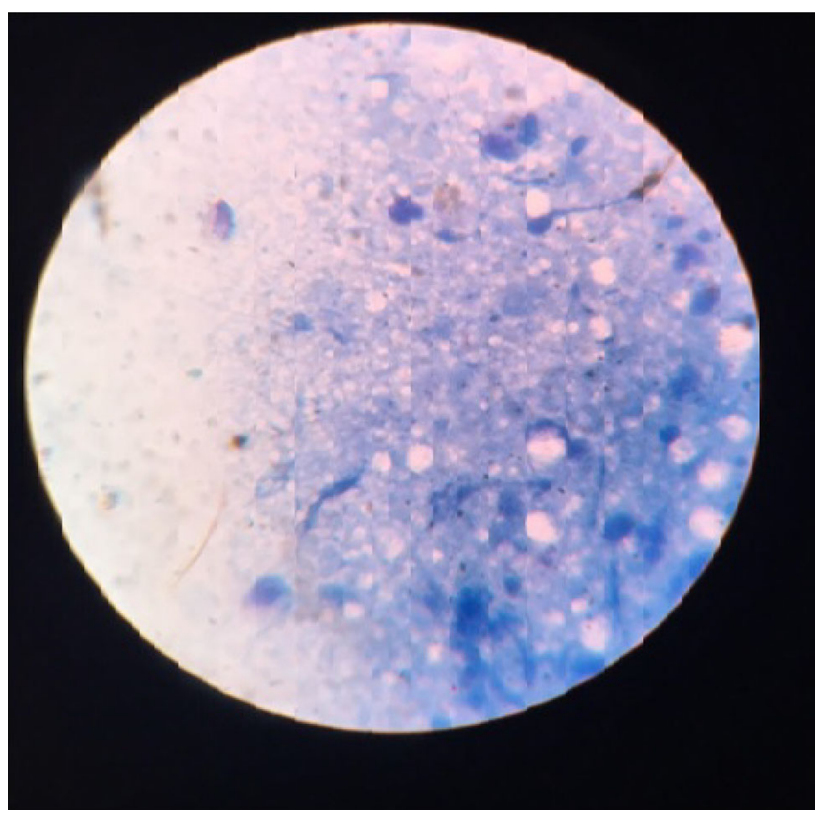

Fig. 2 Histopathological slide showing malignancy

\section{Discussion}

Diagnosis on the basis of cytology with sufficient material is equally significant as histo-pathology [11].

The pattern of lymphadenopathy is important to manage the cases promptly and adequately because of the infections of oral cavity, ear and nose there are number of cases of acute lymphadenitis. Fine needle aspiration cytology has been important tool to make the diagnosis in cervical lymphadenopathy.

In present study more than half $(51.56 \%)$ cases of cervical lymphadenopathy are reactive non-specific, 
(28.12\%) cases are due to tuberculosis, and (17.18\%) are metastatic carcinoma. In present study 34 male and 30 female participated in the study, age range was 2-80 years. A study done by Shakya et al. [12] shows $50.4 \%$ cases as non-specific and $22.4 \%$ cases to be tuberculosis. In their study $51.4 \%$ cases were male, $48.6 \%$ cases were females and mean age was 25.7 years and nasopharyngeal carcinomas reported as most frequent primary site in cervicalmetastatic lymphadenopathy [13].

\section{Conclusion}

The present study reports majority of the patients with cervical lymphadenopathy are reactive non-specific followed by tuberculosis and then by malignancy. FNAC is good tool to diagnose the condition and start the management accordingly.

Tuberculosis is a potentially serious infectious disease, and one of the most common disease affecting the lymph nodes. It is a curable with anti-tubercular drugs if administered as per the accepted regimen. The clinical symptoms in cervical lymphadenopathy have limited clinical significance and the clinical behavior can be highly variable. Dependence on clinical evidence alone would lead to erroneous diagnosis in considerable number of cases. FNAC can be deemed as a frontline investigation with further investigations on the basis of FNAC result. However, histo-pathological examination remains the most dependable diagnostic tool. Most of the diseases are medically curable with limited role of surgery in nonneoplastic lesions. It is important to have a high index suspicion in the Head and Neck region and an Otolaryngologist must be aware about the possible pathologies in cervical lymphadenopathy, then only an early diagnosis can be possible with simple investigations. This can therefore lead to better outcome of treating cervical lymphadenopathy.

\section{Compliance with Ethical Standards}

Conflict of interest There is no conflict of interests from any of the authors.
Ethical Approval The study was performed after proper informed consent from the patient and after proper approval from the ethical committee of the institution.

\section{References}

1. Mili MK, Phookan J (2015) A clinico-pathological study of cervical lymphadenopathy. Int J Dent Med Res 1(5):24-27

2. MacGregor FB (2015) Tumours and cysts of the head and neck. In: Musheer Hussain S (ed) Logan turner's diseases of the nose, throat and ear: head and neck surgery, 11 th edn. CRC Press, Boca Raton

3. Wirth T, Hildebrand F, Allix-Béguec C, Wölbeling F, Kubica T, Kremer K et al (2008) Origin, spread and demography of the Mycobacterium tuberculosis complex. PLoS Pathog 4(9):e1000160. doi:10.1371/journal.ppat. 1000160

4. Lopez B, Agular D, Orozco H, Burger M, Espitia M, Ritacco V, Berrera L, Kremet K, Hemandez-Pando R, Huygen K, Van Sooligen D (2003) A marked difference in pathogenesis and immune response induced by different Mycobacterium tuberculosis genotypes. Clin Exp Immunol 133(1):30-37. doi: 10.1046/j.1365-2249.2003

5. Pareek M, Evans J, Innes J, Smith G, Hingley-Wilson S, Lougheed KE, Sridhar S, Dedicoat M, Hawkey P, Lalvani A (2013) Ethnicity and mycobacterial lineage as determinants of tuberculosis disease phenotype. Thorax 68(3):221-229. doi: 10.1136/thoraxjnl-2012-201824

6. Rozovsky K, Hiller N, Kopelwitz BZ, Simonovsky N (2010) Does $\mathrm{CT}$ have an additional diagnostic value over ultrasound in the evaluation of acute inflammatory neck masses in children? Eur Radiol 20:484-490

7. Shas A, Webber C, Marti J (1986) Fine needle aspiration in the diagnosis of cervical lymphadenopathy. Am J Surg 12(4):420-423

8. Sharma RA (2005) Diagnostic cytopathology. In: Mohan H (ed) Textbook of pathology, 5th edn. Jaypee Brothers, New Delhi, p 22

9. Swartz MA, Lund AW (2012) Lymphatic and interstitial flow in the tumour microenvironment linking mechanbiology with immunity. Nat Rev Cancer 12:210-219

10. Malavar M, Jajoo ILN, Swaroop K, Gupta OP, Juin AP, Poflee VW (1991) A clinical evaluation of fine needle aspiration cytology in the diagnosis of the lymphadenopathy. Ind J Tuberc 38:17

11. Koss LG (1994) Diagnostic cytopathology and the histopathological basis, 4th edn. Lippincott Company, Philadelphia, pp 194-198

12. Shakya G, Malla S, Shakya KN, Shreshtha R (2009) A study of FNAC of cervical lymph nodes. J Nepal Res Counc 7(14):1-5

13. Hsu C, Lenug BSY, Lau SK, Sham JST, Choy D, Engzell U (2006) Efficacy of fine needle aspiration and sampling of lymph nodes in 1,484 Chinese patients. Diagn Cytopathol 6(3):154-159 